\title{
Optimization in the Selection of Sugarcane Varieties in a Sucro Energy Plant Located in the State of São Paulo, Brazil
}

Ricardo Ghantous Cervi ${ }^{1}$, Helenice de Oliveira Florentino Silva ${ }^{2}$, Ernée Kozyreff Filho ${ }^{1}$, Gislaine Cristina Batistela $^{1}$ and Danilo Simões ${ }^{1}$

1. Department of Production Engineering, São Paulo State University (UNESP), Itapeva, São Paulo 18409-010, Brazil

2. Department of Biostatistics, Biosciences Institute, São Paulo State University (UNESP), Botucatu, São Paulo 18618-689, Brazil

\begin{abstract}
Sugarcane crops have undergone several changes with the intensification of agricultural machinery in Brazil in the last years. This occurs, mainly, due to the transfer of the semi-mechanized system to the mechanized one during harvest operations. Thus, studies are needed on the optimization of sugarcane production in relation to mechanized processes, since it is necessary to verify the adaptability of sugarcane varieties to the mechanization of the plantation. This study aimed to develop and apply a mathematical model of optimization to select sugarcane varieties that maximize production and meet the quality standards required by the industry for sugar and fiber contents. The data were collected in a sugarcane mill located in the interior of São Paulo state. The result obtained by the optimization process evinced an increase of $16.65 \%$ when compared to the productivity of the initial scenario.
\end{abstract}

Key words: Integer linear programming, mathematical model, mechanization, operational efficiency, sugarcane culture.

\section{Introduction}

Sugarcane is the main raw material for the production of sugar and ethanol in Brazil, besides being one of the most traditional and important agricultural crops in the country. The accumulated Brazilian production resulted in 651,841 thousand tons in 2016/2017 harvest [1].

The state of São Paulo is the largest producer in the country and responsible for about $60 \%$ of the production of its main derivatives: ethanol and sugar. Regarding sugarcane, the state's production equals $83 \%$ of the world's second largest producer, India. This represents a larger production than the other four major world producers combined, namely China, Thailand, Pakistan and Mexico [2].

The harvesting system used was semi-mechanized a short time ago, with the previous burning of

Corresponding author: Ricardo Ghantous Cervi, Ph.D., research fields: agribusiness management and rural economy. sugarcane, manual cutting and loading of the entire sugarcane by means of machines. However, the harvesting system has undergone many changes in recent years, with the transfer of the semi-mechanized system to the mechanized one. Self-propelled harvesters are used in the mechanized system, which are responsible for cutting, cleaning and transferring sugarcane to transshipment vehicles or directly to transportation vehicles, such as trucks.

This change has occurred for a number of factors, such as cost and supply of manual harvesting labor reduction, and especially the agri-environmental protocol proposed by the sugarcane industry association (União da Indústria de Cana-de-açúcar-UNICA), in partnership with the government of São Paulo, signed in 2007. The agreement aimed to anticipate, in lands with slope up to $12 \%$, the deadline for eliminating sugarcane burning from 2021 to 2014. For lands with slope lager than $12 \%$, considered to be non-mechanizable, the 
deadline has changed from 2031 to 2017. As a result, adherence to the cooperation protocol gives producers an Agri-environmental Compliance Certificate, which provides important advantages in the certification of their products for export [3].

However, the effects of traffic on agricultural areas are frequently reported [4], and they point out that the roots of the majority of plant species are unable to penetrate deeper in the profile when there is compaction in the topsoil. Both the use and the intensity of trafficking, as it causes the process of compaction, are the variables that should be taken into consideration [5].

The heavy traffic of the machines in areas that were not properly systematized causes the trampling of the sugarcane rows resulting in loss of vigor, failure, as well as in the lower development and population of the plants in the subsequent harvests, due to the damage caused to the sugarcane ratoon [6].

Technological advances play an important role in the development of sugarcane crop. The genetic improvement of the plant, associated with better management practices, is responsible for an increase in productivity of $0.43 \mathrm{t} / \mathrm{ha}$ per year [7].

Recent studies have been carried out to analyze the factors that affect the productivity of the sugarcane crop. Moraes et al. [8] observed the interference of different types of soil preparation and planting system on the agronomic characteristics and sugarcane productivity. Silva et al. [9] verified the productivity and technological quality of sugarcane in two agricultural crops, cane plant and cane ratoon, under the influence of organic and mineral fertilization sources.

There are many variables for the choice of varieties to be planted, such as adaptability to mechanized processes, maturation, root sprouting, productivity ( $\mathrm{t} / \mathrm{ha}$ and total recoverable sugar (TRS) $\mathrm{kg} / \mathrm{ha}$ ), technological characteristics required by industry as sucrose (percentage of oligosaccharides-POL) and fiber content, as well as its adaptation to the production environment [10].

The standard sugarcane, in technological and economic conditions of industrial processing, should present sucrose content (sugarcane POL) of approximately $12.5 \%$. Lavanholi [11] also describes that fiber levels of sugarcane stalks should be in the range of $8 \%-14 \%$.

Varieties are considered very productive when sugarcane $\mathrm{POL}$ is higher than $14 \%$, average production between $12.5 \%$ and $14 \%$, and are considered little productive when POL is lower than $12.5 \%$ [12].

The mechanization of sugarcane plants in their agricultural activities demands mechanisms of data quantitative analysis for monitoring of crop productivity, since it is necessary to verify the adaptability of sugarcane varieties with mechanization.

This study aimed to propose and apply a mathematical optimization model to select sugarcane varieties that maximize production and meet the quality standards required by the industry regarding sugar and fiber contents.

\section{Materials and Methods}

The data used in this study were made available by a sugarcane mill located in São Paulo state, referring to a growing area located in the geographical coordinates of latitude $22^{\circ} 32^{\prime} 40.67^{\prime \prime} \mathrm{S}$ and longitude $48^{\circ} 34^{\prime} 11.79^{\prime \prime} \mathrm{W}$. The climate of the region is Cfa type (Method of Köeppen): hot temperate climate, mesothermic, humid and with average annual temperature of $21{ }^{\circ} \mathrm{C}$ [13]. Therefore, this work is characterized as a case study.

In 2011, this property presented a harvested area of 400.17 ha and in this site both the harvesting and the sugarcane loading without previous burning in 12 lots were performed through a mechanized system. At the site there were eight varieties of sugarcane arranged in 10 lots and two additional lots in which the varieties were planted in unspecified proportions. 
An initial scenario was determined, in which data on the average productivity (t/ha), fiber $(\%)$ and POL (\%) were used for the first four years of the analyzed lots from 2008 to 2011. With this information, the average production in the period was estimated.

There is a significant variation in the productivity and technological quality of sugarcane varieties in the first four years of harvest, which are directly influenced by the harvesting system used [14]. The sugarcane analyses of fiber (\%) and POL (\%) were carried out by the laboratory of the plant. Thus, documentary surveys were conducted in the company databases.

In order to solve the proposed mathematical model, the average of the productivity indicators $(\mathrm{t} / \mathrm{ha})$, fiber (\%) and POL (\%) of 25 sugarcane varieties from the first to the fourth harvest were used, which were also harvested under mechanized processes by the sugarcane mill in the period from 2008 to 2011. In this set of data, the eight varieties described in the initial scenario were also included.

These sugarcane varieties were the most used by the mill in its properties located around the plant, where the area studied is also located. This dataset was used so that the optimization process could be carried out with the use of real data, which portrays the daily agricultural activities of the analyzed plant.

Considering the practical importance of data evaluation of this nature and the exploratory nature of this study, the analytical procedures can be used, as long as the conclusions are restricted to the analyzed dataset.

The mathematical model used to maximize sugarcane production is now presented. Let $n$ be the number of sugarcane varieties adaptable to the local environment and let $k$ be the number of lots available for planting. It is desired to determine the variety $i$, $i=1, \ldots, n$, to be planted in lot $j, j=1, \ldots, k$, in order to maximize the sugarcane total production, respecting the limits of fiber and POL established by the plant.

The mathematical model is:

$\operatorname{Maximize} \sum_{i=1}^{n} \sum_{j=1}^{k} S_{i} L_{j} X_{i j}$

Subject to $\sum_{i=1}^{n} \sum_{j=1}^{k} A_{i} L_{j} X_{i j} \geq \bar{A} \sum_{j=1}^{k} L_{j}$

$\bar{F}_{I} \sum_{j=1}^{k} L_{j} \leq \sum_{i=1}^{n} \sum_{j=1}^{k} F_{i} L_{j} X_{i j} \leq \overline{F_{S}} \sum_{j=1}^{k} L_{j}$

$$
\sum_{j=1}^{k} L_{j} X_{i j} \leq \bar{L} \sum_{j=1}^{k} L_{j} \quad i=1, \ldots, n
$$

$\sum_{i=1}^{n} X_{i j}=1$

$j=1, \ldots, k$

$X_{i j} \in\{0,1\}$

$i=1, \ldots, n$,

$j=1, \ldots, k$

The decision variables $X_{i j}$ are binary: $X_{i j}=$ 1 indicates that variety $i$ will be planted in lot $j$, and $X_{i j}=0$ indicates otherwise. The coefficients of the objective function (1) are the products $S_{i} L_{j}$, where $S_{i}$ is the sugarcane productivity of the variety $i$, in $\mathrm{t} / \mathrm{ha}$, and $L_{j}$ is the area of lot $j$, in ha.

In restriction (2), $A_{i}$ is the POL of the variety $i$. This restriction ensures that the average amount of POL produced is greater than or equal to a predetermined quantity $\bar{A}$, here established at $12.5 \%$ [11].

In restriction (3), $F_{i}$ is the fiber percentage of variety $i$, and the restriction ensures that the total percentage of the harvest is between a lower limit $F_{I}$, and a higher limit $F_{S}$, set at $8 \%$ and $14 \%$, respectively. According to Lavanholi [11], sugarcane is considered mature in this range of percentage, according to its chemical composition.

Constraints (4) limit the percentage $\bar{L}$ of the total area that can be planted with only one sugarcane variety. In this study, $\bar{L}=15 \%$ was used, according to MAPA [15], to minimize the risks of disease infestations in the sugarcane crop.

Constraints (5) impose that exactly one variety of 
sugarcane should be planted in each lot and restriction (6) defines the domain of the variables.

The proposed mathematical model was solved using Gurobi 7.0.1 software on a computer with Intel i5 CPU 2.67 GHz and 4 GB RAM.

\section{Results and Discussion}

An initial scenario was designed for the analyzed area where the averages from the 1 st to 4 th harvest of the technological indicators analyzed were considered. Thus, an average production of 38,930.69 $\mathrm{t}$ of sugarcane was determined in an area of 400.17 ha, with a total productivity of $97.3 \mathrm{t} / \mathrm{ha}$, as shown in Table 1. At this site, eight varieties of sugarcane distributed in twelve lots were planted. In lots 11 and 12, several varieties of sugarcane were planted in unspecified proportions.

Table 2 shows the averages of the analyzed variables. The number of samples $(y)$ corresponds to the number of lots where the varieties were planted in owned and leased areas of the studied company.

For the selection of the most productive varieties, the ones harvested in the area analyzed in the 2011 crop were also included. However, the "miscellaneous" option, described in the initial scenario, was not considered because there is no way to reproduce exactly the same planting in the next crops, since several varieties were planted in unspecified proportions in these lots.

For the optimized scenario (Table 3), it is proposed to plant sugarcane varieties that were more productive in the lots described in the initial scenario. It should be noted that, for the data used in this study, fiber (\%) and POL (\%) restrictions did not influence the results of the optimization model, since all varieties of the dataset already met the required percentage ranges. However, as the model was developed for a day-to-day situation of agricultural operations, this technological information, fiber $(\%)$ and POL (\%), on sugarcane varieties may change over the planting and harvesting cycles, and thus can be selected in light of the constraints mentioned.

In the optimized scenario, the average productivity of the crop is estimated at $113.5 \mathrm{t} / \mathrm{ha}$, which represents an increase of $16.65 \%$ when compared to the productivity of the initial scenario of $97.3 \mathrm{t} / \mathrm{ha}$.

In view of the optimized scenario presented, the varieties SP 813250 and RB 835486 were selected,

Table 1 Technological information on analyzed varieties harvested in 2011.

\begin{tabular}{|c|c|c|c|c|c|c|}
\hline Lot & Variety & $\begin{array}{l}\text { Average productivity } \\
\text { (t/ha) from the } 1 \text { st to } 4 \text { th } \\
\text { term }\end{array}$ & $\begin{array}{l}\text { Harvested area } \\
\text { (ha) }\end{array}$ & $\begin{array}{l}\text { Quantity harvested } \\
\text { (t) }\end{array}$ & $\begin{array}{l}\text { Average fiber }(\%) \\
\text { from the } 1 \text { st to } 4 \text { th } \\
\text { harvest }\end{array}$ & $\begin{array}{l}\text { POL (\%) average } \\
\text { from the } 1 \text { st to } 4 \text { th } \\
\text { harvest }\end{array}$ \\
\hline 1 & SP 813250 & 109.15 & 53.18 & $5,804.60$ & 11.7 & 14.07 \\
\hline 2 & SP 813250 & 109.15 & 49.64 & $5,418.21$ & 11.7 & 14.07 \\
\hline 3 & SP 813250 & 109.15 & 41.06 & $4,481.70$ & 11.7 & 14.07 \\
\hline 4 & SP 803280 & 89.46 & 50.36 & $4,505.21$ & 12.68 & 14.96 \\
\hline 5 & PO 8862 & 97.07 & 17.76 & $1,723.96$ & 12.48 & 13.73 \\
\hline 6 & PO 8862 & 97.07 & 31.65 & $3,072.27$ & 12.48 & 13.73 \\
\hline 7 & SP 891115 & 104.39 & 25.55 & $2,667.16$ & 12.02 & 13.58 \\
\hline 8 & RB 855453 & 99.7 & 26.36 & $2,628.09$ & 12.42 & 14.26 \\
\hline 9 & RB 835486 & 108.71 & 1.69 & 183.72 & 12.6 & 15.19 \\
\hline 10 & RB 855536 & 91 & 28.32 & $2,577.12$ & 12.52 & 14.09 \\
\hline 11 & Miscellaneous & 78.41 & 51.93 & $4,071.83$ & 11.87 & 14.46 \\
\hline 12 & Miscellaneous & 79.26 & 22.67 & $1,796.82$ & 11.42 & 14.29 \\
\hline Total & & & 400.17 & $38,930.69$ & & \\
\hline
\end{tabular}


Table 2 Productivity, fiber (\%) and percentage of oligosaccharides (POL) (\%) contents of sugarcane varieties (averages from the 1st to 4th harvest).

\begin{tabular}{|c|c|c|c|c|}
\hline Variety & $\begin{array}{l}\text { Productivity } \\
\text { (t/ha) }\end{array}$ & $\begin{array}{l}\text { Fiber } \\
(\%)\end{array}$ & $\begin{array}{l}\text { POL } \\
(\%)\end{array}$ & $y$ \\
\hline CTC 15 & 110.12 & 11.50 & 13.26 & 120 \\
\hline CTC 16 & 102.87 & 12.19 & 13.91 & 10 \\
\hline CTC 2 & 92.39 & 12.42 & 14.85 & 155 \\
\hline CTC 5 & 96.37 & 11.93 & 14.43 & 10 \\
\hline СТC 6 & 121.64 & 11.31 & 14.18 & 58 \\
\hline СТC 9 & 118.20 & 11.54 & 13.74 & 39 \\
\hline IACSP93-3046 & 101.44 & 12.03 & 15.50 & 59 \\
\hline IACSP95-5000 & 110.61 & 11.34 & 12.63 & 38 \\
\hline PO $8862 *$ & 97.07 & 12.48 & 13.73 & 626 \\
\hline RB 835486* & 108.71 & 12.60 & 15.19 & 13 \\
\hline RB 855156 & 96.70 & 11.75 & 13.75 & 374 \\
\hline RB $855453 *$ & 99.70 & 12.42 & 14.26 & 287 \\
\hline RB 855536* & 91.00 & 12.52 & 14.09 & 241 \\
\hline RB 867515 & 92.35 & 12.48 & 14.13 & 5,520 \\
\hline RB 925211 & 105.70 & 11.94 & 13.05 & 1,085 \\
\hline RB 935744 & 93.81 & 12.57 & 13.59 & 559 \\
\hline RB 946903 & 110.21 & 11.35 & 13.14 & 50 \\
\hline RB 965902 & 107.31 & 12.12 & 13.33 & 54 \\
\hline RB 965917 & 114.65 & 11.40 & 13.24 & 36 \\
\hline SP 791011 & 99.34 & 13.61 & 14.54 & 80 \\
\hline SP 801816 & 99.68 & 12.23 & 13.48 & 55 \\
\hline SP 801842 & 94.45 & 12.50 & 14.26 & 1,134 \\
\hline SP $803280^{*}$ & 89.46 & 12.68 & 14.96 & 160 \\
\hline SP $813250 *$ & 109.15 & 11.70 & 14.07 & 650 \\
\hline SP 891115* & 104.39 & 12.02 & 13.58 & 256 \\
\hline
\end{tabular}

* Varieties harvested in 2011.

Table 3 Proposal of variety planting in an optimized scenario.

\begin{tabular}{|c|c|c|c|c|c|c|}
\hline Lot & Variety & $\begin{array}{l}\text { Productivity (t/ha) } \\
\text { average from the } \\
\text { 1st to 4th harvest }\end{array}$ & $\begin{array}{l}\text { Area } \\
\text { (ha) }\end{array}$ & $\begin{array}{l}\text { Amount to be } \\
\text { harvested }(\mathrm{t})\end{array}$ & $\begin{array}{l}\text { Fiber (\%) average } \\
\text { from the } 1 \text { st to } 4 \text { th } \\
\text { harvest }\end{array}$ & $\begin{array}{l}\text { POL (\%) average } \\
\text { from the } 1 \text { st to } 4 \text { th } \\
\text { harvest }\end{array}$ \\
\hline 1 & RB 965917 & 114.65 & 53.18 & $6,096.85$ & 11.40 & 13.24 \\
\hline 2 & SP $813250^{*}$ & 109.15 & 49.64 & $5,418.43$ & 11.70 & 14.07 \\
\hline 3 & CTC 9 & 118.20 & 41.06 & $4,853.09$ & 11.54 & 13.74 \\
\hline 4 & CTC 15 & 110.12 & 50.36 & $5,545.79$ & 11.50 & 13.26 \\
\hline 5 & СТС 9 & 118.20 & 17.76 & $2,099.15$ & 11.54 & 13.74 \\
\hline 6 & СTC 6 & 121.64 & 31.65 & $3,849.99$ & 11.31 & 14.18 \\
\hline 7 & RB 946903 & 110.21 & 25.55 & $2,815.85$ & 11.35 & 13.14 \\
\hline 8 & RB 946903 & 110.21 & 26.36 & $2,905.12$ & 11.35 & 13.14 \\
\hline 9 & RB 965917 & 114.65 & 1.69 & 193.75 & 11.40 & 13.24 \\
\hline 10 & CTC 6 & 121.64 & 28.32 & $3,444.92$ & 11.31 & 14.18 \\
\hline 11 & IACSP95-5000 & 110.61 & 51.93 & $5,744.15$ & 11.34 & 12.63 \\
\hline 12 & RB 835486* & 108.71 & 22.67 & $2,464.42$ & 12.60 & 15.19 \\
\hline Total & & & 400.17 & $45,431.52$ & & \\
\hline
\end{tabular}

* Varieties harvested in 2011. 
which were already planted in 2012. However, the variety RB 835486 was changed from lot 9 to lot 12 and SP 813250 variety was maintained in lot 2 . The two most productive varieties, CTC 6 and CTC 9, are suggested for planting in lots 6 and 10 (CTC 6) and 3 and 5 (CTC 9), and they correspond to $31.36 \%$ of the estimated total production.

Several studies on mathematical modeling have been developed with the purpose of assisting agricultural operations in the sugar-alcohol sector, which are described below. Lemos et al. [16] used the Data Envelopment Analysis (DEA) technique, which is based on non-parametric mathematical models, to analyze the efficiency of sugar-alcohol plants in the periods from 2005/2006 to 2014/2015.

Borodin et al. [17] presented an overview of the use of recent operational research methodologies to deal with uncertainties in the management of the agricultural supply chain. Jena and Poggi [18] provided mathematical models using mixed integer programming for the tactical and operational planning of sugarcane harvesting. Oliveira Florentino and Pato [19] developed bi-objective optimization models for the selection of sugarcane varieties that meet environmental and economic requirements.

Colin [20] used a quadratic programming model to develop sugarcane crop planning. Higgins and Davies [21] applied computational simulation to plan the capacity of the sugarcane transport system. Salassi et al. [22] presented a proposal that assists in the choice of the sugarcane harvesting system, through the application of a mixed integer programming model.

\section{Conclusions}

Optimization models using linear programming can help the agents of the sugar-alcohol industry in the selection of sugarcane varieties to make year-to-year combinations, considering the historical data of sugarcane harvesting areas.

This optimization process also contributes to selecting the varieties that are adaptable to soil and local environment and which present higher productivity with the adoption of mechanized harvesting and loading operations.

The collection and storage of data, the use of analysis tools and the subsequent monitoring of information on processes involving sugarcane cultivation, from planting to harvesting, are important for monitoring the effects of intensive use of mechanization in the exploitation of the culture.

\section{References}

[1] UNICA-União da Indústria de Cana de Açúcar (Sugarcane Industry Union). 2019. Production and Grinding History. Accessed March 18 2019. http://www.unicadata.com.br/pdfHPM.php?idioma=1\&ti poHistorico $=4 \&$ idTabela $=1984 \&$ produto $=\&$ safra $=2016 / 2$ $017 \&$ safraIni $=\&$ safraFim $=\&$ estado=RS,SC,PR,SP,RJ,M G,ES,MS,MT,GO,DF,BA,SE,AL,PE,PB,RN,CE,PI,MA, TO,PA,AP,RO,AM,AC,RR.

[2] Rudorff, B. F. T., Aguiar, D. A., Silva, W. F., Sugawara, L. M., Adami, M., and Moreira, M. A. 2010. "Studies on the Rapid Expansion of Sugarcane for Ethanol Production in São Paulo State (Brazil) Using Landsat Data." Remote Sensing 2 (4): 1057-76.

[3] Novaes, M. R., Rudorff, B. F. T., Almeida, C. M., and Aguiar, D. A. 2011. "Spatial Analysis of the Sugarcane Crop Burning Reduction: Future Perspectives to the Fulfillment of the Agri-environmental Protocol." Agricultural Engineering 31 (3): 572-83. (in Portuguese)

[4] Botta, G. F., Tolón-Becerra, A., Bienvenido Rivero, E. R. D., Laureda, D. A., Contessotto, E. E., Fonterosa, R. A., and Agnes, D. W. 2018. "Traffic of Harvester Combines: Effect on Maize Yields (Zea mays L.) and Soil Compaction under Direct Sowing System." Journal of the Faculty of Agricultural Sciences 50 (1): 85-100. (in Spanish)

[5] Laureda, D. A., Botta, G. F., TolónBecerra, A., and Rosatto, H. G. 2016. "Soil Compaction Induced by Machinery at Polo Fields in Argentina." Journal of the Faculty of Agricultural Sciences 48 (1): 79-99. (in Spanish)

[6] Benedini, M. S., and Conde, A. J. 2008. "Ideal Planting Spacing for Sugarcane Mechanized Harvesting." Coplana 52 (1): 26-8. (in Portuguese)

[7] Gouvêa, J. R. F., Sentelhas, P. C., Gazzola, S. T., and Santos, M. C. 2009. "Climate Changes and Technological Advances: Impacts on Sugarcane Productivity in Tropical Southern Brazil." Agricultural Scientia 66 (5): 593-605. 
[8] Moraes, E. R., Domingues, L. A. S., Medeiros, M. H., Peixoto, J. V. M., and Lana, R. M. Q. 2016. "Productivity and Agronomic Characteristics of Sugarcane under Different Soil Tillage Systems." Journal of Neotropical Agriculture 3 (1): 27-32. (in Portuguese)

[9] Silva, W. P., Almeida, C. D. G. C., Silva, V. G. F., Bastos, G. Q., and Marques, K. P. P. 2014. "Productivity and Technological Quality of Sugar Cane under Different Nutrient Sources." Brazilian Journal of Irrigated Agriculture 8 (6): 476-87. (in Portuguese)

[10] Barbosa, V. F. A. M. 2013. "Planting Systems." In Sugarcane: From Planting to Harvesting, edited by Santos, F., and Borém, A. Viçosa, Minas Gerais State: UFV, 27-48. (in Portuguese)

[11] Lavanholi, M. G. D. P. 2008. "Quality of Sugarcane as Raw Material for Sugar and Alcohol Production." In: Sugarcane, edited by Dinardo-Miranda, L. L., Vasconcelos, A. C. M., and Landelli, M. G. A. Campinas, São Paulo State: Agronomic Institute, 697-722. (in Portuguese)

[12] Ripoli, T. C. C., and Ripoli, M. L. C. 2009. Sugarcane Biomass: Harvest, Energy and Environment, 2nd ed. Piracicaba: Esalq, 333.

[13] Cunha, A. R., and Martins, D. 2009. "Climatic Classification for the Districts of Botucatu and São Manuel, SP.” Irriga. 14 (1): 1-11. (in Portuguese)

[14] Sartori, M. M. P., Florentino, H. O., Basta, C., and Leão, A. L. 2001. "Determination of the Optimal Quantity of Crop Residues for Energy in Sugarcane Crop Management Using Linear Programming in Variety Selection and Planting Strategy." Energy 26 (11): 1031-40.

[15] MAPA-Ministério da Agricultura, Pecuária e Abastecimento (Ministry of Agriculture, Livestock and
Supply). 2008. Orange Rust: Imminent Threat to Brazilian's Sugarcane Fields. Accessed January $16^{\text {th }}$, 2018. http://www.agricultura.gov.br/arq_editor/file/ ferrugem1.pdf. (in Portuguese)

[16] Lemos, S. V., Salgado Júnior, A. P., Duarte, A., Antunes, F. A., and Esteves, R. L. 2016. "Comparative Analysis between Agricultural and Industrial Productivity of the Brazilian Sugar-Energy Sector in the Last 10 Years." Costs and Agribusiness on Line 12 (4): 154-74. (in Portuguese)

[17] Borodin, V., Bourtembourg, J., and Labadie, N. 2016. "Handling Uncertainty in Agricultural Supply Chain Management: A State of the Art." European Journal of Operational Research 254 (2): 348-59.

[18] Jena, S. D., and Poggi, M. 2013. "Harvest Planning in the Brazilian Sugarcane Industry via Mixed Integer Programming." European Journal of Operational Research 230 (2): 374-84.

[19] Oliveira Florentino, H., and Pato, M. V. 2014. "A Bi-objective Genetic Approach for the Selection of Sugarcane Varieties to Comply with Environmental and Economic Requirements." Journal of the Operational Research Society 65 (6): 842-54.

[20] Colin, E. C. 2009. "Mathematical Programming Accelerates Implementation of Agro-Industrial Sugarcane Complex." European Journal of Operational Research 199 (1): 232-5.

[21] Higgins, A. J., and Davies, I. A. 2005. "Simulation Model for Capacity Planning in Sugarcane Transport." Computers and Electronics in Agriculture 47 (2): 85-102.

[22] Salassi, M. E., Breaux, J. B., and Naquin, C. J. 2002. "Modeling Within-Season Sugarcane Growth for Optimal Harvest System Selection." Agricultural System 73 (1): 261-78. 